\title{
Vital Bleaching of Tetracycline-Stained Teeth by Using KTP Laser: A Case Report
}

\author{
Jun-Ichiro Kinoshita \\ Hamid Jafarzadeh ${ }^{b}$ \\ Maryam Forghanib
}

\section{ABSTRACT}

Bleaching of discolored teeth is one of the most important topics in aesthetic dentistry. A great challenge in this area is obtaining good results in tetracycline-stained teeth. The wavelength and features of KTP laser, which is a type of Nd:YAG laser, seem to be appropriate for bleaching of these teeth. This case report underlines the importance of knowledge about the photochemical bleaching by using the KTP laser and its side effects on soft tissues. (Eur J Dent 2009;3:229-232)

Key words: KTP laser; Bleaching; Tetracycline.

\section{INTRODUCTION}

The general population relates new dentistry to improved aesthetics and social success. Tooth bleaching is the most commonly requested elective cosmetic service in most dental offices. ${ }^{1}$

Tetracycline-stained teeth are one of the most difficult cases for achieving acceptable results of bleaching. Tetracycline, when consumed during the developmental period of the teeth, will result in a characteristic blue-gray or yellow-brown opalescent discoloration of the dentin. This is

a Department of Clinical Cariology and Endodontology, Showa University School of Dentistry, Tokyo, Japan.

b Department of Endodontics, Faculty of Dentistry and Dental Research Center, Mashhad University of Medical Sciences, Mashhad, Iran.

Corresponding author: Dr. Hamid Jafarzadeh Faculty of Dentistry and Dental Research Center Vakilabad Blvd, P.O. Box: 91735-984, Mashhad, Iran. Phone: +985118829501

Fax: +985117626058

E-mail: hamid_j365dayahoo.com JafarzadehBHamums.ac.ir thought to be a photo-initiated reaction, explaining why the incisors tend to be more affected than the molars. ${ }^{1}$

Tooth shade depends on the type of tetracycline, dosage, duration of intake, and patient's age at the time of administration. Discoloration is usually bilateral, affecting multiple teeth in both arches. Deposition of the tetracycline may be continuous or laid down in stripes depending on whether the ingestion was continuous or interrupted. ${ }^{2}$

Two approaches have been used to treat tetracycline discoloration: (i) bleaching the external enamel surface ${ }^{3-5}$ and (ii) intracoronal bleaching following intentional root canal therapy. ${ }^{6-8}$

Some types of lasers can be used for extracoronal bleaching. These include the argon laser, carbon dioxide $\left(\mathrm{CO}_{2}\right)$ laser, and diode laser. ${ }^{2}$ Recently, a new type of laser called KTP laser is getting more and more popular in Europe and Japan. This laser has been used in plastic 
surgery (e.g., removing tattoo, hemangioma, and melanosis) with acceptable results. ${ }^{9-11}$

The present report describes the vital bleaching of tetracycline-stained teeth by using KTP laser.

\section{CASE REPORT}

A 32-year-old male Japanese patient with the chief complaint of teeth discoloration was referred to the Showa University School of Dentistry, Tokyo, Japan. In clinical examination, yellowish colors of the cervical aspect of all teeth in addition to dark calculus were observed (Figure 1). Informed consent was obtained after the explanation of what was expected by the bleaching treatment by using KTP laser.

In the beginning of the treatment, by using VITAPAN classical shades guide (Vita Zahnfabric, Bad Säckingen, Germany), original color shade was recorded as $\mathrm{C} 4$ to be used as a baseline, and then, the crown surface was polished for removing the organic substances (Figure 2).

$35 \%$ hydrogen peroxide gel (Smartbleach, SBI nv., Herzele, Belgium), with $\mathrm{pH}$ around 10, was prepared after mixing with buffering powder just before the treatment. Hydrogen peroxide can easily damage soft tissues, so light-curing soft composite resin (Smartblock, SBI nv., Herzele, Belgium) was placed at the marginal borders as a gum protector (Figure 3). Bleaching gel was placed on the tooth surface, and KTP light (SmartLite, Deka, Frenze, Italyl by $532 \mathrm{~nm}$ wavelength and 1 watt power was irradiated for 30 seconds for each tooth. The distance between the instrument tip and tooth surface was kept at $10 \mathrm{~mm}$. Circular motion was employed to prevent overheating.

After finishing of the irradiation, fluoride gel was applied on the treated surface of the teeth; and then, in order to prevent post-treatment hypersensitivity, KTP laser by 1 watt power was irradiated again for 15 seconds. The first session stopped here; however, sessions can be repeated up to 3 times in each appointment, if necessary.

After only one session of KTP bleaching, almost all of treated teeth had B2 shade in the cervical area (Figures 4-6).

The peroxide burn of the gingiva around lower left premolars showed a side effect of using hydrogen peroxide, possibly because composite block was insufficient. This was possibly due to the incomplete drying of the surface before blocking which resulted in gingival inflammation. The patient complained of pain a little just after the session but not insisted on stopping the treatment. Vitamin E ointment (Maruha, Tokyo, Japan) was applied to the marginal gingiva for help to healing. After 30 minutes, the pain was disappeared and the color of the gingiva returned to the original pink appearance.

\section{DISCUSSION}

KTP (Karium-Titanium-Phosphoric acid), which is a type of $\mathrm{Nd}: Y A G$ laser, seems to be appropriate for bleaching of tetracycline-stained teeth. When Nd:YAG laser beam lwavelength: $1064 \mathrm{~nm}$ ) goes through the solid medium of KTP crystal, its wavelength decreases into $532 \mathrm{~nm}$, just half of the original wavelength. This means KTP has very similar characteristics to $\mathrm{Nd}: \mathrm{YAG}$, plus that a few unique characteristics can be added. ${ }^{12}$

Green visible light of KTP is absorbed well in hemoglobin and melanin ${ }^{13-15}$ but not in hydroxyapatite or water. ${ }^{16}$ KTP tends to penetrate into dentin with less damage. This laser does not increase temperature much. Its photons have high energy that facilitate the chemical and photodynamic reactions without damage to both hard and pulp tissues. ${ }^{17-21}$ It has been shown that KTP laser is capable of producing significantly more effect than LED or diode laser. ${ }^{17}$

Because of small molecular weight of hydrogen peroxide, it can penetrate into organic substances among hydroxy-apatite crystals. By KTP laser's efficient acceleration, hydrogen peroxide cuts the chain and open the carbon rings, resulting in brightening the color of collagen. ${ }^{12,22,23}$

Among many kinds of lasers, KTP is cooler in temperature and stronger in photon energy, which means KTP is suitable for vital teeth bleaching without damage to pulp tissue. ${ }^{18-21}$ When an appropriate outer energy is applied, the number of radical oxide in the gel grows rapidly and they penetrate deeper into dentin. Then strong energy of photons from KTP runs after the radical oxide into very deeper area, due to the fact that KTP penetrate dentin easily to accelerate the whole chemical reactions.

Painless irradiating procedure enables operator to do sufficient irradiation on vital teeth. In this case, after 30 seconds of irradiation, fluoride gel was applied on the treated tooth 
surface. This procedure prevents hypersensitivity that contributes to whitening treatment by stuffing open dentinal tubules at cervical area.

If the soft tissues near the cervical area be exposed to $35 \%$ hydrogen peroxide, the gingival surface would be burned and the patient would report some pain; however, the symptoms are not severe, and will return to normal status within 30

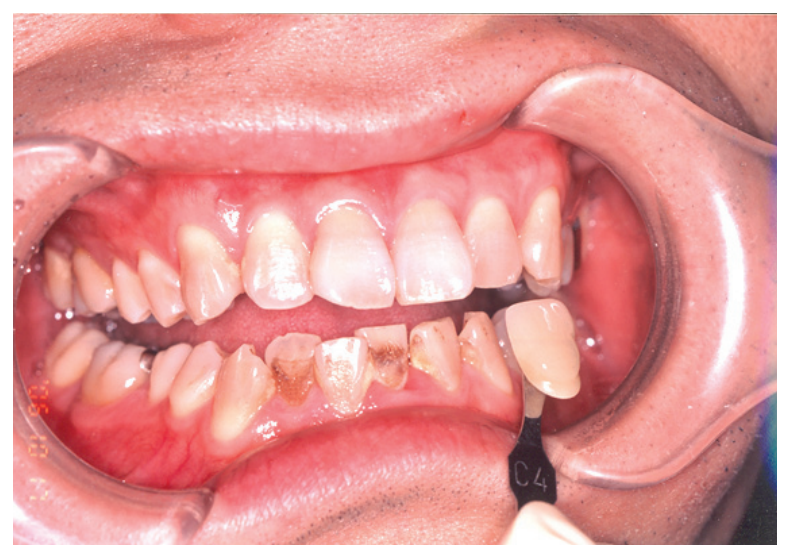

Figure 1. Before treatment, calculus and discoloration were observed. Shade-taking resulted in $\mathrm{C} 4$.

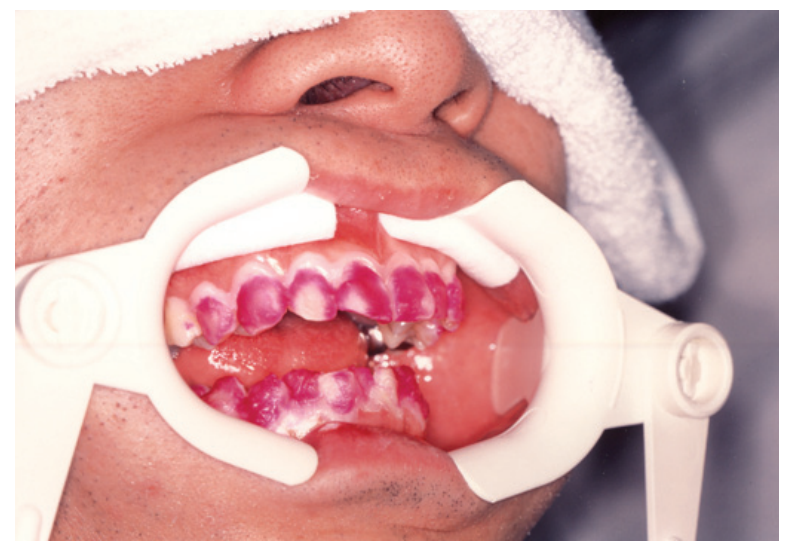

Figure 3. After 30 seconds' irradiation for each tooth: Half of the hydrogen peroxide gel was vaporized off. Gum protector (light-cured soft composite resin) is recognized.

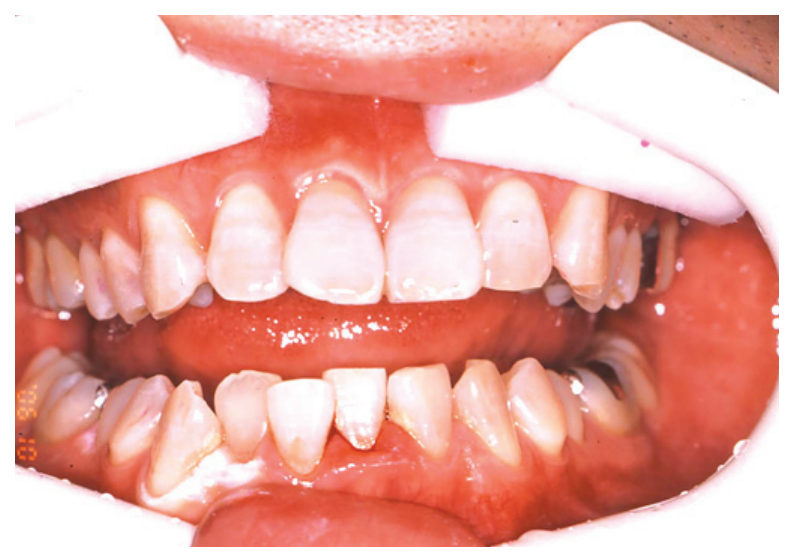

Figure 5. Gum protector was easily removed with exploring needle. Shade evaluation showed 1 session dramatically changed teeth color from $\mathrm{C} 4$ to $\mathrm{B} 2$. minutes after the application of vitamin E ointment. This accident can be avoided by appropriate guarding by soft composite resin or ointment placed on the margins on the tooth surface.

\section{CONCLUSIONS}

Vital bleaching by using KTP laser could be achieved in shorter time than simple chemical

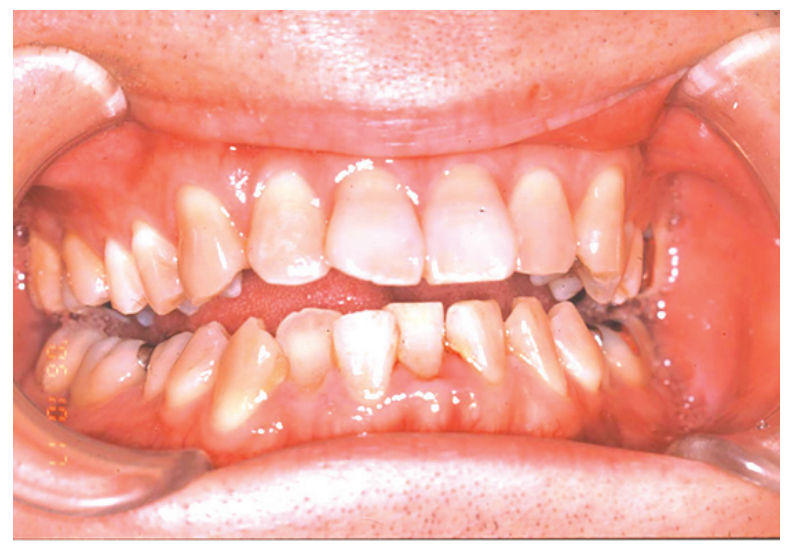

Figure 2. After polishing: Diagnosed was tetracycline-staining by inquiries about medical history.

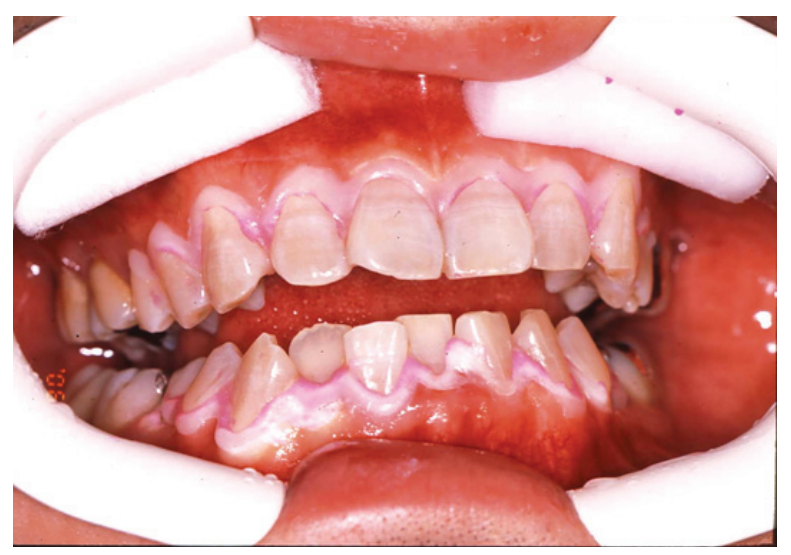

Figure 4. After wiping off the gel.

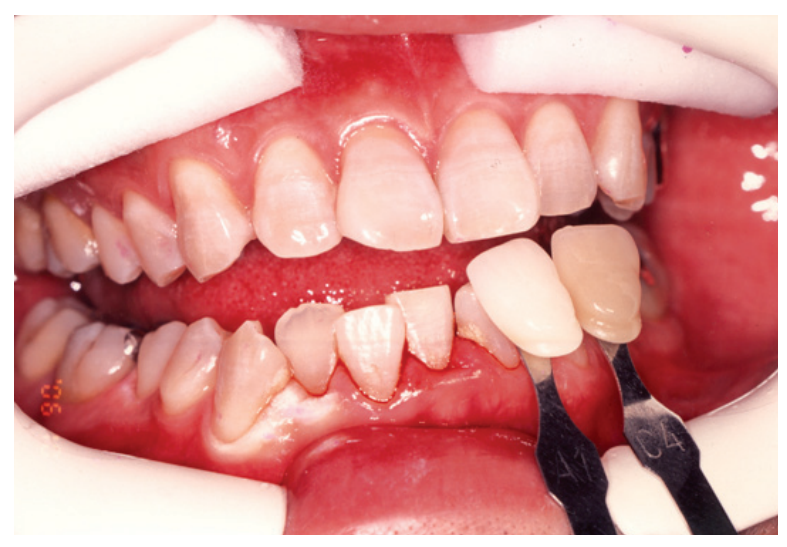

Figure 6 . After finishing only 1 session of vital teeth bleaching: The border line between tetracycline-affected area and nonaffected area, which was hypocalcified, could be recognized. 
treatment. No damage to the vital pulp and hard tissue crystals are other benefits; however, future studies should confirm this. Slight injury to the gingiva cannot always be prevented, so the protecting and healing methods must be improved. Hypersensitivity and gingival injury after bleaching must be avoided. Careful case selection is recommended.

\section{ACKNOWLEDGEMENT}

This case report was partially financed by “High-Tech Research Center" Project for Private Universities: matching fund subsidy from MEXT (Ministry of Education, culture, Sports, Science and Technology), 2005-2009. It is also partially financed by Grants-in-Aid for Scientific Research (C) (20592336-0010, 063262201629B) from the Japan Society for the promotion of Science (JSPS).

\section{REFERENCES}

1. Cohen S, Burns RC. Pathways of the Pulp. Mosby, St. Louis 2002.

2. Ingle JI, Bakland LK. Endodontics. B. C. Decker Inc., London 2002.

3. Jordan RE, Boksman L. Conservative vital bleaching treatment of discolored dentition. Compend Contin Educ Dent 1984;5:803-805.

4. Arens DE, Rich JJ, Healey HJ. A practical method of bleaching tetracycline-stained teeth. Oral Surg Oral Med Oral Pathol 1972;34:812-817.

5. Cohen S, Parkins FM. Bleaching tetracycline-stained vital teeth. Oral Surg Oral Med Oral Pathol 1970;29:465-471.

6. Abou-Rass M. The elimination of tetracycline discoloration by intentional endodontics and internal bleaching. $J$ Endod 1982;8:101-106.

7. Lake FT, O'Dell NL, Walton RE. The effect of internal bleaching on tetracycline in dentin. J Endod 1985;11:415420.

8. Walton RE, O'Dell NL, Lake FT, Shimp RG. Internal bleaching of tetracycline-stained teeth in dogs. $J$ Endod $1983 ; 9: 416-420$.

9. Gorouhi F, Davari P, Kashani MN, Firooz A. Treatment of traumatic tattoo with the Q-switched Nd:YAG laser. $J$ Cosmet Laser Ther 2007;9:253-255.

10. Hazarika P, Pillai S, Jacob SM, Punnoose SE, Roy A. Application of potassium-titanyl-phosphate (KTP) laser in the excision of pyriform fossa hemangioma. $\mathrm{Am} \mathrm{J}$ Otolaryngol 2006;27:136-138.
11. Mattes D, Reich EM, Muellner K, Langmann G. Evaluation of a KTP (potassium-titanyl-phosphate) $532 \mathrm{~nm}$ laser for endovaporization of choroidal melanomas. Lasers Surg Med 2005;36:57-64.

12. Lin LC, Pitts DL, Burgess LW Jr. An investigation into the feasibility of photobleaching tetracycline-stained teeth. $J$ Endod 1988; 14:293-299.

13. Bachmann A, Ruazat R. The KTP-(greenlight) laser principles and experiences. Minim Invasive Ther Allied Technol 2007;16:5-10.

14. Tope WD, Kageyama N. "Hot" KTP-laser treatment of facial angiofibromata. Lasers Surg Med 2001;29:78-81.

15. Goldberg DJ. Laser removal of pigmented and vascular legions. J Cosmet Dermatol 2006;5:204-209.

16. Schoop U, Kluger W, Dervisbegovic S, Goharkhay K, Wernisch J, Georgopoolos A, Sperr W, Moritz A. Innovative wavelengths in endodontic treatment. Lasers Surg Med 2006;38:624-630

17. Zhang C, Wang X, Kinoshita J, Zhao B, Toko T, Kimura Y, Matsumoto K. Effects of KTP laser irradiation, diode laser, and LED on tooth bleaching: a comparative study. Photomed Laser Surg 2007;25:91-95.

18. Moritz A, Beer F, Verheyen P, Wernisch J, Schoop U, Blum R, Walsh LJ. Oral Laser Applications. Quintessence, Berlin 2006.

19. Nammour S, Rocca JP, Keiani K, Balestra C, Snoeck T, Powell L, Reck JV. Pulpal and periodontal temperature rise during KTP laser use as a root planing complement in vitro. Photomed Laser Surg 2005;23:10-14.

20. Machida T, Wilder-Smith P, Arrastia AM, Liaw LH, Berns MW. Root canal preparation using the second harmonic KTP:YAG laser: A thermographic and scanning electron microscopic study. J Endod 1995;21:88-91.

21. Tewfic HM, Pashley DH, Horner JA, Sharawy MM. Structural and functional changes in root dentin following expose to KTP/532 laser. J Endod 1993;19:492-497.

22. Davies AK, McKellar JF, Phillips GO, Reid AG. Photochemical oxidation of tetracycline in aqueous solution. $J$ Chem Soc Perkin 1979;2:369-375.

23. Davies AK, Cundall RB, Dandiker Y, Slifkin MA. Photooxidation of tetracycline adsorbed on hydroxyapatite in relation to the light-induced staining of teeth. $J$ Dent Res 1985;64:936-939. 